\title{
What We Are Talking About When We Talk About Social Media: A Framework For Study
}

Jeffrey W. Treem

Assistant Professor

The University of Texas at Austin, Communication Studies

2504A Whitis Ave. (A1105)

Austin, USA 78712

jtreem@austin.utexas.edu

$=$

Stephanie L. Dailey

Assistant Professor

Texas State University, Communication Studies

Centennial Hall, Room 205

601 University Drive

San Marcos, USA 78666

dailey@txstate.edu

Casey S. Pierce

University of Michigan, School of Information

4322 North Quad

105 S. State St.

Ann Arbor, USA 48109-1285

cbspierc@umich.edu

Diana Biffl

The University of Texas at Austin, Communication Studies

2504A Whitis Ave. (A1105)

Austin, TX, USA 78712

dtbiffl@utexas.edu

This is the author manuscript accepted for publication and has undergone full peer review but has not been through the copyediting, typesetting, pagination and proofreading process, which may lead to differences between this version and the Version of Record. Please cite this article as doi: $10.1111 / \operatorname{soc} 4.12404$

This article is protected by copyright. All rights reserved. 


\section{What We Are Talking About When We Talk About Social Media: \\ A Framework For Study}

Abstract: Social media continues to grow as a focus of social, organizational, and scholarly interest, yet there is little agreement as to what constitutes social media and how it can be effectively analyzed. We review various definitions of social media and note that much of the confusion regarding social media comes from conflation between social media types, platforms, and activities. To facilitate investigations of social media we debunk common social media myths and review the relationship between social media and several prominent sociological concerns. We conclude by reflecting on directions for future research on social media.

This article is protected by copyright. All rights reserved. 


\section{What We Are Talking About When We Talk About Social Media: $\longrightarrow$ $=2$ \\ A Framework For Study}

Social media matters. It is used by protest groups opposing oppressive government action (Benski, Langman, Perugorria, \& Tejerinaand 2013; Freelon, Mcilwain, and Clark 2016; Hänska-Ahy 2014; Tinati, Halford, Carr, and Pope 2014), and by individuals seeking opportunities to express their identities to others (Marwick and boyd 2010; Murthy 2012; Robards and Bennett 2011; van Dijck 2013). Social media matters because it can be a resource for individuals seeking social support to navigate difficult life situations (DeAndrea, Ellison, LaRose, Steinfeld, Fiore 2012; Eichhorn 2008), and because it creates a digital record of our behaviors that can be used by corporations or researchers (Fuchs 2014; Humphreys and Wilken 2015; Mayer-Schoenberger and Cukier 2013). Over the past two decades social media has evolved from an obscure, yet novel form of communication to an increasingly ubiquitous means of interaction, organizing, information gathering, and commerce. Yet as social media has grown to a multi-billion dollar sector of the global economy and become a common term in our daily lexicon, understanding the scope and nature of social media activity has become more difficult to discern. To address this challenge, we explore definitions of social media; address several social 
media myths and misconceptions; examine how social media relates to several sociological concerns; and discuss how scholars might study social media moving forward.

\section{Defining social media}

\section{What is social media?}

While there are disputed claims as to who coined the term "social media," the term appears to have emerged in the early 1990s in reference to emerging web-based communication tools that facilitated online interaction (Bercovici 2010). However, providing a single definition that encompasses all of the technologies and activities associated with social media is extremely difficult, in part because social media is not defined by any specific scope, format, topic, audience, or source. This potential expansive definition of social media is demonstrated by Trottier and Fuchs (2015), who note that when considering the nature of social media theorists could reasonably adopt any of three forms of sociality as a focal point: a) cognition, b) communication, or c) cooperation. Each of these views of what constitutes sociality directs analytical attention to different social processes and different types of media. A focus on cognition is concerned with shared knowledge and therefore media, such as newspapers, websites, or even television, which provide masses with access to similar information would operate as social media. Foregrounding communication directs attention to social relations and interactions and therefore media such as email, chat, or discussion forums would all fit within the scope of social media. Lastly, cooperation deals with interdependent acts toward a communal goal and is reflected in media such as Wikipedia, or even certain massively-multiplayer online 
role-playing games (MMORPGs). Importantly, one's definition of social media may differ based on their theoretical stance and analytical concerns, and definitions of social media need not necessarily be focused on internet-based media developed in recent decades.

Despite the potential for broad definitions of social media, in practice most scholars and practitioners invoking social media are referring to a specific set of online offerings that have emerged over the past three decades - including blogs, social networking sites, and microblogging. The emergence of these technologies and the associated specific applications is often characterized as establishing Web 2.0, which refers to the presence of a class of web-based applications that offered all users the opportunity to write and contribute through posting content, and could be accessed through multiple devices (Beer and Burrows 2007a). In fact, some scholars eschew the term social media in favor of the construct Web 2.0 which can operate as an umbrella concept that encompasses a broader group of online applications that facilitate expression and interaction, (Beer 2008). Specifically, scholars have called for distinctions between social media broadly, and more narrow terms such as social networks or social networking sites. For instance, Murthy (2012) argues that Twitter is a form of social media in that it facilitates user-generated public communication by non-professional actors, but differentiates Twitter from social networking sites like Facebook or LinkedIn where individuals commonly interact with people they know offline and following of activity is bi-directional. Similarly, Beer (2008) argues that there is value in distinguishing among sites that are used primarily for the purposes of individuals actively networking - social networking sites - and 
platforms that simply articulate the online connections of individuals, which would fall under the definition of social network sites. He comments that classifying social media can facilitate more nuanced scholarship examining similarities and differences among types of applications and their respective uses.

For those seeking to provide an operational definition as to what constitutes social media there appear to be two approaches: the attribute approach and the typology approach. First, the attribute approach focuses on enumerating the basic aspects a communication technology needs to be considered social media. Following this approach, Kietzmann et al. (2011) defined social media with a broad stroke in that social media "employ[s] mobile and web-based technologies to create highly interactive platforms via which individuals and communities share, co-create, discuss, and modify user-generated content" (241). With the aim of better explaining social media, they also proposed seven functional building blocks of social media: identity, conversations, sharing, presence, relationships, reputation, and groups. Although each block adequately represents a particular aspect of the social media experience, this attribute approach does not clearly explain what social media looks like in a practical sense. Kane, Alavi, Labianca and Borgatti (2014) focus on social media networks and argue they are defined by a digital profile authored by users, the ability to search content and restrict others from viewing content, means of displaying relational ties, and network transparency that reveals the connections of other users. These definitions are purposively inclusive to not only account for current social media platforms, but to also provide a framework for analyzing new and emerging technologies. 
With slight variations, these definitions of social media commonly focus on three attributes: 1) they are web-based, 2) they provides a means for individuals to connect and interact with content and other users, and 3) they provide the means for users to generate and distribute content on the respective platforms.

Second, scholars have created classifications that define social media in terms of different types of communication technologies (i.e. Kaplan and Haenlein 2010; Krishnamurthy and Dou 2008; Shao 2009). For example, Kaplan and Haenlein (2010) classify social media in terms of blogs, social networking sites, virtual social worlds, collaborative projects, content communities, and virtual game worlds. Alternatively Beer (2008) offers the categories of wikis, folksonomies, mashups, and social networking sites as distinct types of applications that fit within the broader framework of Web 2.0. Other scholars focus on definitions of singular social media types. Ellison and boyd (2013, p. 158) specifically distinguish social network sites as communication platforms that offer users unique profiles, public connections, and the ability to create and consume user-generated content (and do consider Twitter and Youtube social network sites). Blogs, another type of social media technology, developed a unique form that included distinct entries in reverse chronological order (Siles 2011), whereas microblogging, a phenomenon largely driven by Twitter, founded in 2006, focuses on much shorter live updates of one's life, opinions, or reactions to current events or other media (Honeycutt and Herring 2009; van Dijck 2011). 
The uniting aspects of all of these types of social media technologies are that they create a way for individuals to maintain current relationships, to create new connections, to create and share their own content, and, in some degree, to make their own social networks observable to others (Ellison and boyd 2013; Heinonen 2011; Kietzmann, Hermkens, McCarthy and Silvestre 2011; Romero, Galuba, Asur and Huberman 2011; Qualman 2012). We do not seek to provide a singular, universal definition of social media here, nor do we aim to provide a distinct classification system of different social media types, platforms, or specific services. Instead, we argue that the ambiguity around social media should not be viewed by scholars as a source of frustration, but rather an avenue for ongoing analytical exploration. It offers opportunities to consider the extent to which differences in the features of technologies, the goals of users, or the context of use all serve to provide (or undermine) distinctions among social media. Ultimately, in the absence of explicit criteria most people defining social media default to the view Supreme Court Justice Potter Stewart adopted when struggling to define pornography: "I know it when I see it" (Jacobellis v. Ohio 1964; Treem and Thomas 2010).

Social media as technology and activity

Another challenge in analyzing social media is that scholars often conflate the technology itself (and its bundles of features) with the ways people use them. In other words, it is important to disentangle blogs or Twitter as technologies from the actions of blogging or tweeting. One of the reasons this distinction is necessary is because use of social media by individuals is often misinterpreted as solely an active, visible process. However, social media users do not always 
engage in public acts of personal expression or communication; they may simply use social media as a means of entertainment or information gathering.

Hence, we conceptualize social media activity as comprised of a variety of behaviors that vary in the level of effort exhibited by users, and how visible the actions, and related interactions and communication, are to others. For instance, the majority of social media activity consists of what is often derisively called "lurking" (Nonnecke and Preece 2000), and involves users consuming social media content without making their actions visible online. This is exemplified by users who have social media accounts, but whose uses are characterized by observing, even tracking, the activity of other users - often people they may know offline. This provides individuals access to information without the need to actively ask questions, initiate conversation, or engage in active self-presentation. Importantly, though these individuals are passive in that they are recipients of social media content produced by others, they still actively participate in social media by constituting an audience and community for others to orient to (Litt 2012), and their activity could be appropriately characterized as listening in that they are directing attention to forms of communication (Crawford 2009).

Other users of social media undertake moderately visible actions in relation to existing content, such as liking a Facebook post, favoriting a Tweet, or voting in a poll. These activities can serve as signals to content contributors regarding the popularity or interest an audience has related to a particular form of communication. These feedback mechanisms, such as the number of comments on a post, or the number of views for a video, can operate as central motivators for 
social media producers to continue providing content and participating actively (Yardi, Golder and Brzozowski 2009). Additionally, though not comprising original content, these actions produce data regarding the behaviors and interests of individuals that can be used by organizations for commercial purposes (Gerlitz and Helmond 2013).

Finally, social media users can create original or remixed (e.g.,memes, gifs, mashups) content and post that content online, a behavior that is typically publicly visible to other users on a respective platform. This possibility for user-generated content is considering a distinctive aspect of social media and can be contrasted with mass media such as television or radio where users do not have similar access to the means of production. It is important to note that though content created on social media is often completely public, most social media applications provide features designed to restrict access to material to individuals or groups selected by the content provider. In practice, individuals may participate in a mix of more or less visible or effortful behaviors when using different forms of social media, and seek to interact (or restrict interaction) with particular groups. Therefore, we can understand social media participation as constituted by a web of interdependent behaviors that are not merely reflected in visible media use.

Beyond clearly conceptualizing individual social media participation, it is also important to distinguish between the forms of technology referenced when people refer to social media. In this paper we distinguish between types of social media (i.e., blog, social networking site, microblogging, wikis), specific social media platforms (Blogger, Tumblr, Facebook, Twitter, 
Snapchat), and social media activities (i.e., blogging, Facebooking, Tweeting). Although types of social media are likely to share many features, platforms can differ wildly in terms of the expected behaviors and symbolic aspects of use. For instance, if all you knew about an individual was that she was very active on LinkedIn, you might infer that she was looking for a job or engaged in professional networking behaviors. Alternatively, if all you knew about an individual is that they were very active on MySpace, you might infer that they are a musician or artist. Both LinkedIn and MySpace are social networking sites, but the platforms are perceived and used differently. Though social media is often treated as a singular form of technology, it is comprised of different types and platforms and there are practical, technical, and symbolic differences between them that are important to recognize.

Another way of drawing distinctions (or similarities) between or among social media is by viewing them as constituting genres of communication. A genre is a "distinctive type of communicative action, characterized by a socially recognized communicative purpose" (Orlikowski and Yates 1994, 543). Genres have two aspects: the form, which is the recognizable features and appearance, and the substance, which are the topics, themes, categories, arguments, subjects that signify the purpose of the communication. Social media platforms, and the behaviors they enable, can also be viewed as representative of genres of communication. For instance, the form of social networking sites often includes a profile page representing an individual user. Furthermore, we might expect the substance of content on a blog hosted by The 
New York Times to be focused on news, while the blog authored by your friend backpacking through Europe to be more informal and personal.

The current dominance of particular social media sites means that they may be viewed as genres unto themselves, with people referring to other technologies as "like Facebook" or "like Twitter." Alternatively, social media activity can be treated as separate genres that have distinct forms and substance. For example, individuals could have a separate personal and professional social networking profile that they would curate differently to present and discuss different topics. Blogs can operate as personal journals, platforms for social commentary, or stores of knowledge, each of which would be associated with particular topics of discussion and modes of participation (Herring et al. 2004). In sum, social media is constituted by a diverse set of communicative genres, some of which largely reflect the online evolution of existing genres (i.e., news reporting, organizational customer service) and others that are largely unique to social media (i.e., profile pages, online diaries). When individuals refer to social media types, they are often referring to a particular genre of social media, and understanding this can help establish a common ground in discussions about social media types, platforms, and activities.

\section{Social media myths}

The confusion around the definition of social media and what constitutes social media is exacerbated by certain erroneous beliefs regarding the use of social media. Therefore, in an effort to further facilitate a common ground for the analysis of social media we address a number of these myths. 
Social media is overtly social

At first glance, the term "social" could be viewed as implying that behaviors involve active interaction with others. This is in line with the communicative and cooperative forms of sociality noted earlier (Trottier and Fuchs 2015). Nonetheless, claiming that "all social media is social" is an oversimplification of what being social online really means. In reality, participation is primarily from a silent majority who do not visibly engage in discussions or posting, but instead watch and listen to what others do online (Nonnecke and Preece 2000; Crawford 2009). For instance, the average Facebook user accesses more content than they actually share compared to "power users" who are responsible for consistently contributing high volumes of content (Hampton, Goulet, Marlow and Rainie 2012). Similarly, most Wikipedia users do not edit entries, but participate as receptive article readers (Panciera, Halfaker and Terveen 2009).

These non-visible forms of sociality are critically important as they are the means by which social media becomes a common source of shared social information, and this participation forms an audience that invites further social action. Although contributors may not directly interact with the silent majority, when individuals engage with or publish content on social media they do so with an "imagined audience" in mind who will view their communicative acts (Litt 2012). Thus, social activity encompasses both the active content contribution alongside the gathering of and listening to that content. However, the dominant form of participation may be overlooked because it is not in line with the active personal 
expression more often associated with social media. Non-visible participation in social media is not the same as non-use (Baumer, Burrell, Ames, Brubaker and Dourish 2015). Social media reflects public opinion or sentiment

Considering Shirky's $(2011,28)$ statement that "public opinion relies on both media and conversation," it is certainly the case that social media is evolving as a platform for civic deliberation and a forum for the exchange of ideas. Following this view and the allure of analyzing large corpora of data, social media activity is increasingly used as measures for public opinion. Researchers have shown the correlation between traditional polling and using data from sites like Twitter (O’Connor, Balasubramanyan, Routledge and Smith 2010) and have recognized the blogosphere as an important source of public opinion (Kietzmann, Hermkens, McCarthy and Silvestre 2011).

However, there is a critical distinction between recognizing social media as a space where public opinion is shaped, developed, and debated, and mistakenly concluding that social media content is a valid reflection of where public opinion stands. Because a disproportionate amount of content comes from a small number of users, sentiments on social media do not necessarily reflect the majority's perceptions and may lack cross-cultural awareness (Hecht and Gergle 2010). Researchers can address this issue by considering the biases inherent in particular social media datasets due to the fact certain demographics use particular platforms in unique ways compared to other social groups (boyd and Crawford 2012).

Social media is new 
It may seem as if social media is a relatively recent phenomenon that did not exist prior to the dawn of the Internet; however, the social acts of gathering, commenting and disseminating information existed long before the creation of digital social media platforms. Accounting for the ways in which non-digital media - drawings, letters, books, newspapers - are also social, reminds us that social media has existed for quite some time. While the advancements of digital platforms such as Facebook, Twitter and Instagram may be technically novel compared to nondigital forms of social media, a historical account of social media highlights how people are fundamentally social beings with a predisposition for sharing, connecting, and collectively consuming.

For example, the circulation of handwritten letters in the early Christian church as well as printed newsletters in pre-Revolutionary France both illustrate how information about a gospel of a new faith and gossip about an unfavorable monarchy were widely spread using non-digital social media (Standage 2013). As these messages were shared, they became viral in similar ways that a tweet, blog post, or a meme is shared and gains visibility among a larger group of people. Moreover, one of the first multipage newspapers in the US, Publick Occurrences, published in 1690 purposely inserted a blank page for readers to write their own "status updates" and "comments" before sharing their annotated copy with another reader (DiPiazza 2012). In this way, the sharing of content and critique on a printed newspaper reflects early digital versions of blogging and online citizen journalism. Such historical examples of social media, long before the 
Internet, prompt us to consider how social media has evolved from other forms of media that support communication and social interactions across time and space.

\section{Social media is not serious}

Another myth about social media is that it is primarily for sharing of pop cultural phenomena, comedic memes, or quotidian snapshots of food. For some, social media is deemed as a technology promoting narcissism (Leung 2013; Ryan and Xenos 2011) and unproductivity (Karr-Wisniewski and Lu 2010; Tarafdar, Tu, Ragu-Nathan and Ragu-Nathan 2014). Others have questioned how online activism inflates perceptions of what activism actually means (Christensen 2011, Earl and Kimport 2011) suggesting that the ability to effortlessly support a particular issue without engaging in any offline action has perpetuated lackluster "clicktivism" or "slacktivism" social engagement. These perspectives have facilitated a view that social media is only for inconsequential activities.

However, it is important to recognize the potential instrumentality of the technology. Social media has contributed to the development of policies in the domains of science (Rotman, Preece, Hammock, Procita, Hansen, Parr, Lewis and Jacobs 2012) and government (Bertot, Jaeger and Grimes 2010). Additionally, social media can play an active role in establishing and legitimizing social movements (AlSayyad and Guvenc 2015; Benski, Langman, Perugorría and Tejerinaand 2013), and the informal, engaging nature of the media may in fact facilitate these movements. Specific to the arena of public health, Twitter has been used for monitoring the spread of epidemics (Paul and Dredze 2011) and alerting the public with pertinent information 
about natural disasters (Liu, Fraustino and Jin 2015). And research has found that online communities provide valuable social support for individuals battling illness such as eating disorders (Eichhorn 2008) and breast cancer (Shaw, Hawkins, McTavish, Pingree and Gustafson 2006). Additionally, though individuals may initially use social media for one reason (i.e., entertainment or communication with friends) uses of social media may change for individuals as their demands and lifestyles change. Robards (2012) studied social media users in Australia who had shifted use from Myspace to Facebook and noted that the change occurred simultaneously with "growing up," as Myspace was viewed as for younger individuals and Facebook as more appropriate for adults. Moreover, parents indicate they use social media sites like Facebook for information and support related to parenting issues (Duggan, Lenhart, Lampe and Ellison 2015) and social media increasingly plays a role in how individuals seek employment opportunities (Stephens and Dailey 2014). These examples highlight how social media can reflect individuals' unique needs and changing lifestyles, and can indeed be applied and instrumental for serious use.

\section{Sociological concerns and social media}

Regardless of differing views or misperceptions related to the exact nature of what constitutes social media, it is clear that social media has relevance to a number of areas of sociological concern. Social media presents new possibilities for social actions, and new ways of understanding the behaviors of individuals and groups. In this section, we briefly address domains where scholars have explored the significance of social media. Although each section is 
worthy of more in-depth review independently, our description is designed merely to sketch the scope of social media's relevance in these areas.

\section{Construction and presentation of selfhood}

A great deal of contemporary theorizing in sociology and related disciplines has explored the construction and presentation of selfhood via social media (Hogan 2010; Murthy 2012, Nadkarni and Hofmann 2012; Robards and Bennett 2011; van Dijck 2013). Specifically, this literature advances the position that participation with social media provides myriad opportunities for individuals to attempt the construction, affirmation, obfuscation, or alteration of identities. Murthy (2012) addresses this issue in his analysis of how sociological theory can help scholars understand social media, drawing heavily upon Goffman's (1959) work on selfpresentation and the dramaturgical view of social interaction. He notes that "users of social media continue to post regularly as the status updating practice becomes a meaningful part of their identities" (1062). This expression of identity is not merely for self-affirmation, but as a means of conveying a particular performance of self and facilitating engagement with others. In discussing the use of social networking sites as a way for youths to connect with one another Robards and Bennett $(2011,308)$ commented, "Performing identity online is essential to facilitate social interaction." They examined the use of social networking sites by 32 "young people" (participants ranged from 18-27 years old) in Australia, and found that individuals expressed themselves on the sites in a manner that reflected and supported their offline networks. Similarly, Marwick and boyd (2010) studied Twitter users and found that individuals tailored 
messages to different audiences, and were strategic and purposeful in how they presented themselves to others. Because social media offer numerous features facilitating expression creating a social media profile, posting status updates, and sharing photographs -individuals have a variety of means to construct and present themselves online (Zhao, Grasmuck and Martin 2008). Through participation in social media, individuals may offer "exhibitions," submitting various artifacts that communicate one's identity to others (Hogan 2010). For instance, Cook and Hasmath (2014) studied Facebook web pages related to the "Slut Walk" movement, and concluded that the social media served as a space for performances of gendered identity, and that these performances could take more creative and expressive forms in an online space unbound from the limits of time and location. At the group level, Stephansen and Couldry (2014) describe how Twitter was used by teachers and students at a school in England to help construct a community of practice (Wenger 1998) in which individuals could identify with colleagues and learn how to act appropriately as members of the department.

Sociologists have argued, however, about the extent to which these online selves are truthful, sincere, or more strategic presentations. On one hand, social media may provide us with more accurate portrayals of others, exposing the "backstage" or private sphere of individuals' lives (Goffman 1959, 119). For example, whereas you might only learn about a certain aspect of a coworker's identity in the workplace, by following your colleague on Instagram, you might gather insight into his or her hobbies and family, gaining a more multidimensional view of your coworker's identity. Your colleague may present him or herself very differently in the office 
(formal performance) than on social media (backstage), where the coworker presents a more truthful portrayal of his or her life. Others argue, however, that "Most likely, we are getting a posed view of the backstage: we see what people want us to/let us see" (Murthy 2012, 1065) For example, the asynchronous nature of communication and the potential to remain anonymous on social media allows users to be more deliberate, strategic, or even deceptive about their selfpresentation (Golder and Macy 2014), and it may be more difficult for individuals to detect this deception (Donath 2009). Overall, social media creates a space for the construction and presentation of selfhood, though the nature of this process and its associated consequences will vary across social contexts and social media types and platforms.

\section{Participatory democracy and social movements}

In comparison to early accounts of social media use dating back to 1997 where participants were early adopters of technology and considered niche users (boyd and Ellison 2008), participating in social media activities has now become commonplace. The increase in social media use and accessibility, and the growing amount of user-generated content available, has raised the question of what, if any, role social media plays in democratizing participation in social and civic life. In particular, the popular press has portrayed social media as a powerful catalyst igniting social movements and political demonstrations. Dubbing social movements with labels such as the "Twitter revolutions" (Sullivan 2009) reifies the view that social media has created a more participatory democracy for users. 
Notably, current events illustrating the use of social media in political activism have focused on the significant role of social media in enabling citizens to mobilize and coordinate their activities (AlSayyad and Guvenc 2015). For example, studies examining social media use during the Arab Spring have suggested hashtag conversations using \#egypt and \#libya fueled participation in the movement to "mediate a wide range of practices of political participation among a diverse group of social media users" (Bruns, Highfield, and Burgess 2013, 1). Similarly, Tinati and colleagues (2014) also note how social networking sites, such as Twitter have expanded the opportunities for activists to mobilize, inform and connect diverse networks of people. These findings are echoed across a number of social movements, including the Occupy Wall Street (Benski, Langman, Perugorria, and Tejerinaand 2013) and the Black Lives Matter movements in the U.S. (Freelon, Mcilwain, and Clark 2016) as well as the 2011 UK riots (Tinati et al., 2014), demonstrating how discontented citizens leveraged social media to engage their communities and to legitimize their message with a global audience.

For instance, the \#blacklivesmatter hashtag did not gain prominence until a year after its first appearance following protests in Ferguson, Missouri; however, the hashtag eventually signified the movement and became a tool for activists to amplify marginalized voices (Freelon et al. 2016). In another case of social media use affecting offline demonstrations, Norwegian citizens created Facebook events to organize the Rose Marches to commemorate victims of the 22/7 terror attacks. In this instance, the Facebook event prompting the Rose Marches demonstrations had a particular influence mobilizing younger and lower socioeconomic 
participants (Enjolras, Steen-Johnsen and Wollebaek 2012). As these cases examining the interplay between social media and social movements illustrate, social media affords people the ability to share and participate in activities that previously would have been inaccessible to them.

While these cases clearly show the impact of social media as a tool for mobilization and a movement toward a seemingly democratization of the web, critical scholars have challenged the utopian view of unhindered participation through social media (Beer 2008; Beer and Burrows 2007b; Fuchs 2014). To this point, critical scholars have poignantly highlighted how corporations' involvement on the Internet skews the utopian ideal of a truly participatory democracy on social media. As Fuchs (2014) notes, "the most popular YouTube videos stem from global multimedia corporations like Universal, Sony and Walt Disney" (61) Furthermore, Fuchs (2014) critiques scholars who overlook the "predominant focus of users is on non-political entertainment" and ignore "questions of who owns, controls and materially benefits from corporate social media" (61). Furthermore, privileging the role of social media technologies in social uprisings may distract from the underlying social problems and make structural change less likely (Fuchs 2012).

Taken together, the affordances of social media do enable vast numbers of people to participate online. However, many of these participants and the content they share are scattered across a multitude of social networking sites and different communities within the same platform. This breadth and diversity of content on social media, challenges the view that democracy requires "some common normative dimensions" (Garnharm 1992, 360). Moreover, given that 
designers with their own motives, and at times capitalist interests create technologies, there is reason to challenge the rhetoric of democratization (Beer 2008) with social media use. Thus scholars will continue to explore the tension between the democratizing potential of social media to lower barriers to collective action, and the frequency with which social media reflects and reifies existing social hierarchies.

\section{Datafication and Dataveillance}

Datafication refers to how technology can quantify human behavior from metadata rendered from such technologies (Mayer-Schoenberger and Cukier 2013), and outlines how this ability to collect data from social media platforms offers researchers, and corporations, the ability to track, monitor and analyze users' in-the-moment activities. Much of the excitement to utilize the data collected from social media platforms has ushered in a new wave of sophisticated methodologies to collect, analyze and translate this data to actionable insights. Such data has been valuable to marketers interested in understanding consumers' buying preferences to customize personalized ads; public health officials identifying health epidemics in communities; and law enforcement increasing surveillance to enhance policing activities (van Dijck and Poell 2013).

While social media datafication offers new sources to assess and understand human behavior cheaply and quickly compared to previous methods, researchers still need to understand how the data was collected, stored, cleaned and analyzed to understand the validity of that data (Driscoll and Walker 2014). On the one hand, the real-time data collected from social media can 
provide an understanding of human behavior and sociality; however, on the other hand, researchers question whether all social media activity accurately reflects live activities (van Dijck 2014; van Dijck and Poell 2013). Activities such as Facebook "friending" and "liking" (Bucher 2012; Gerlitz and Helmond 2013), "following" and "retweeting" on Twitter (Kwak et al., 2010); and connecting with professional colleagues on LinkedIn (van Dijck 2013) have become norms within these platforms, but at times, the data rendered from these platforms pose potential biases and risks in their application. For one, data collected from various social media activities may not accurately reflect sociality offline. Furthermore, access to data through social media creates tensions regarding the appropriate use of this information. For instance, Humphreys and Wilken (2015) noted how small businesses faced a tension between the value of social media data in catering to customers and the trust and privacy expectations the customers had regarding the organization's actions.

Moreover, researchers and practitioners alike should take caution when analyzing and utilizing social media data and not presume such data represents objectivity (van Dijck 2014). Instead, users of data from social media platforms should consider the proprietary methods in which the data is shaped by the platform's algorithms. In other words, social media platforms are not "neutral channels for data transmission" (van Dijck and Poell 2013, 10) and data flows can be manipulated in ways unknown to those using the data (Mahrt and Scharkow 2013). For example, Crawford and Gillespie (2016) examine how flagging behaviors on social media where a user marks their distaste or concern for posted content - can become abstract indicators 
of importance according to the ways in which those flags are culled by the platform's algorithms. Thus, inferring user sentiment by the indication of flagged content should not be taken as an objective measure of human behavior without understanding the invisible ways in which the social media platform may shape visible markers of online activity.

Social media users themselves have also begun to lament their lack of control regarding when and how their online activities are assessed, especially by third parties who have access to their interactions on social media. Van Djick (2009) argues that users now play both the roles of content providers and data providers, hence, datafication as a means to examine human behavior increasingly requires trust in the social media platforms that collect the data. While social media datafication offers revolutionary opportunities to collect and understand human behavior, researchers should understand the implications for analyzing online sociality and translating such insights into actions for the offline world (boyd and Crawford 2012).

\section{Digital social inequalities}

Many scholars have also found interest in the potential digital social inequalities brought about by the proliferation of social media. Interestingly, the conversation regarding online inequality has shifted beyond concerns with access to the technology itself to differences in what individuals can do once they have access. Even if minorities have equal access to social media, the skills that people have to make use of technologies remains unevenly distributed (Golder and Macy 2014). As Atewell $(2001,257)$ explained, "Even if we are able to provide a computer on every desk... Affluent children will leverage their ample resources of social and cultural capital 
to excel." Much of this argument is built upon the theoretical foundation of how virtual communities and social capital are built online. Research suggests that online social networks are commonly built by extending offline relationships (Arora 2012). As Zhao and Elesh (2007) describe in their discussion of unequal access to social capital in the digital world, "It is generally considered inappropriate to approach strangers" online, and social media makes "ignoring contact solicitations from others" easy (p. 179). Although Neves (2013) found a positive relationship between Internet use and social capital—-the resources embedded in an individual's social ties-this association likely only holds for certain social strata. Many individuals are limited in who they can meet and connect with via social media. For example, some applications, such as LinkedIn and Facebook, do not even show certain potential connections unless a mutual friend exists.

Although social barriers to Internet use still exist— for instance Willis and Tranter (2006) found that income, age, and education continue to be social barriers to Internet use in Australia —materially, individuals are increasingly able to connect with anyone at anytime. Thus, digital social inequalities are likely not simply a function of how social media platforms are technically configured online; rather, they result from social norms that pervade social media behaviors. Research has shown that psychological factors, such as perceived competence and both extrinsic and intrinsic motivations, lead people to generate content online (Correa 2010), and this could contribute to demographic differences in social media participation. For example, Hargittai's (2008) study of young adults found that women are more likely to use social networking sites 
than males and Schradie (2012) analyzed data from 13 Internet and American Life Project surveys over a seven-year period, demonstrating that Americans with lower educational levels are less likely to blog. Given the increasingly central role of social media in a variety of social processes, inequities in digital participation may establish or expand existing social divides.

\section{Future Study of Social Media}

It is tautological to state that social media will continue to change in the coming years. This ongoing evolution makes it challenging for scholars hoping to conduct social media research that applies beyond a specific application, set time period, or idiosyncratic context of use. We present two considerations for future studies of social media that might facilitate meaningful theoretical and empirical developments: a) The utilization of big data, and b) Analyzing the socio-technical nature of social media.

\section{Utilization of big data}

As noted earlier, social media use creates a trove of data regarding the attributes of individuals, locations, social connections, topics of conversations, and a host of other information produced through users' participation - what Manovich (2011) calls "Big Social Data." As the number of individuals, and organizations, using social media increases (and new social media applications emerge), the amount of data produced will continue to expand. The availability of data of this size, scope, and scale presents opportunities for scholars to address new research questions. Specifically, the interdependent nature of social media opens up new possibilities for the studies of networks and flows of connections and content (Tinati, Halford, 
Carr and Pope 2014). However, social media researchers will have to determine how to effectively integrate big data into studies, and how to appropriately evaluate the use of work that uses big data. Methodologically, researchers are increasingly using software and services that operate as social media data aggregators and allow researchers to capture and analyze large quantities of social media activity - both the actions taken by individuals and the specific communication provided (Beer 2012). These tools assist both quantitative analysis of actions and the gathering of corpora for qualitative study.

However, there are a number of issues that may undermine the usefulness of large sets of social media data. Bruns (2013) points out that studies utilizing big data are often perceived as being scientific, even when the methods of data gathering may lack rigor. Furthermore, scholars should be aware that the form and features of social media may direct attention to specific units of analysis, and lead researchers to overlook other dynamics present (Burgess and Burns 2012). Given the broad scope of social media data available and the different choices presented to researchers Baym (2013) cautions that, "Claims based on analyses of social media data must be closely scrutinized with an eye toward what they omit, how they may be skewed, and how far they over-reach." As tools develop that make gathering and analyzing large set of social media data more accessible, more scholars will face decisions regarding if, and how, to integrate big data into research.

Analyzing the socio-technical nature of social media 
As social media has become increasingly intertwined with numerous aspects of social life, scholars have recognized the need to move beyond a focus directly on how people use existing social media platforms. Rather, social media use can be analyzed as a socio-technical system (Niederer and van Dijck 2010) in which the specific material features of social media are intertwined with the practices of users of the technology, and the goals of designers of technology. Advocating this perspective, van Dijck $(2012,6)$ urges scholars to consider the ways in which "technology shapes sociality as much as sociality shapes technology" and to understand social media data in the context by which "humans and machines have their own distinctive, but mutually shaping roles." A socio-technical perspective provokes questions related to how differential appropriations of technology at the individual or mirco-levels of society shape processes at the higher levels of analysis such as organizations, institutions, or structures. For example, Gerlitz and Helmond (2013) describe how features provided by Facebook, such as the like button, encourage individuals to interact with content, but that as these features became integrated across online spaces they created new ways for Facebook to track and quantify online behavior, and this information was used to reconfigure how people navigated online material. This socio-technical approach will require researchers to consider both human (i.e. social media users, technology designers) and non human agents (i.e., features of social media platforms, institutional policies) to gain a richer understanding of social media use and associated social change. 
The dynamic nature of social media makes it difficult to predict the specific direction of future research, but we do know that social media is likely to proliferate and mature, contribute to new social divisions, alter how individuals organize and mobilize, and complicate the way organizations and institutions manage information. Thus even as specific social media technologies emerge and others die, it is likely that opportunities for the study of social media will continue to grow.

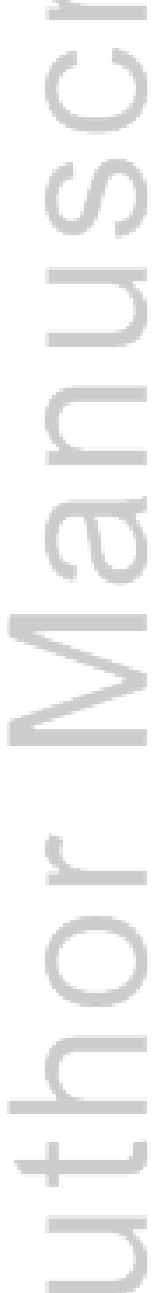

\section{References}

AlSayyad, Nezar and Guvenc, Muna. 2015. "Virtual Uprisings: On the Interaction of New Social 
Media, Traditional Media Coverage and Urban Space during the 'Arab Spring." Urban Studies 52(11): 2018-2034.

Arora, Payal. 2012. "Typology of Web 2.0 Spheres: Understanding the Cultural Dimensions of Social Media Spaces." Current Sociology 60: 599-618.

Atewell, Paul. 2001. “The First and Second Digital Divides." Sociology of Education 74: 252259.

Baumer, Eric P., Jenna Burrell, Morgan G. Ames, Jed R. Brubaker and Paul Dourish. 2015. “On the Importance and Implications of Studying Technology Non-Use." Interactions 22(2): $52-56$.

Baym, Nancy K. 2013. "Data Not Seen: The Uses and Shortcomings of Social Media Metrics." First Monday, 18(7). Available at: http://pear.accc.uic.edu/ojs/index.php/fm/article/view/4873/3752>.

Beer, David. 2008. "Social Network(ing) sites...Revisiting the Story So Far: A Response to danah boyd \& Nicole Ellison.” Journal of Computer-Mediated Communication 13: 516529.

Beer, David. 2012. "Using Social Media Data Aggregators to do Social Research.” Sociological Research Online 17(3): 10, Available at: http://www.socresonline.org.uk/17/3/10.html Beer, David and Roger Burrows. 2007a. "Sociology and, of and in Web 2.0: Some Initial Considerations." Sociological Research Online, 12(5): Available at: http://www.socresonline.org.uk/12/5/17.html

This article is protected by copyright. All rights reserved. 
Beer, David and Roger Burrows. 2007b. "Consumption, Prosumption and Participatory Web Cultures." Journal of Consumer Culture 10(1): 3-12.

Benski, Tova, Lauren Langman, Ignacia Perugorría, and Benjamín Tejerinaand. 2013. "From the Streets and Squares to Social Movement Studies: What Have We Learned?" Current Sociology 61(4): 541-561.

Bercovici Jeff. 2010. "Who Coined "Social Media"? Web Pioneers Compete

For Credit." Forbes. Retrieved from http://blogs.forbes.com/jeffbercovici/2010/12/09/ who-coined-social-media-web-pioneers-compete-for-credit/

Bertot, John C., Paul T. Jaeger and Justin M. Grimes. 2010. "Using ICTs to Create a Culture of Transparency: E-government and Social Media as Openness and Anti-Corruption Tools for Societies." Government Information Quarterly 27(3): 264-271.

boyd, danah and Kate Crawford. 2012. "Critical Questions for Big Data." Information, Communication, and Society 15(5): 662-679.

boyd, danah and Nicole B. Ellison. 2007. "Social Network Sites: Definition, History, and Scholarship.” Journal of Computer-Mediated Communication 13: 210-230.

Bruns, Axel, Tim Highfield, and Jean Burgess. 2013. "The Arab Spring and Social Media Audiences: English and Arabic Twitter Users and Their Networks." American Behavioral Scientist 57(7): 871-898.

This article is protected by copyright. All rights reserved. 
Bucher, Taina. 2012. "Want to Be on Top? Algorithmic Power and the Threat of Invisibility on Facebook." New Media \& Society 14(7): 1164-1180.

Burgess, Jean and Axel Bruns. 2012. "Twitter Archives and the Challenges of 'Big Social Data'" for Media and Communication Research'M_C Journal 15(5): 1-9.

Christensen, C., 2011. “Twitter Revolutions? Addressing Social Media and Dissent.” The Communication Review 14(3): 155-157.

Cook, Julia, and Reza Hasmath. 2014. "The Discursive Construction and Performance of Gendered Identity on Social Media." Current Sociology 62(7): 975-993

Correa, Teresa. 2010. “The Participation Divide Among 'Online Experts': Experience, Skills and Psychological Factors as Predictors of College Students' Web Content Creation.” Journal of Computer-Mediated Communication 16: 71-92.

Crawford, Kate. 2009. "Following you: Disciplines of listening in social media." Continuum:

Journal of Media \& Cultural Studies 23(4): 525-535.

Crawford, Kate and Tarleton Gillespie. 2016. "What is a Flag for? Social Media Reporting Tools and the Vocabulary of Complaint." New Media \& Society 18(3): 410-428.

DeAndrea, David C., Nicole B. Ellison, Robert LaRose, Charles Steinfeld and Andrew Fiore. 2012. "Serious Social Media: On the Use of Social Media for Improving Students' Adjustment to College." The Internet and Higher Education 15(1): 15-23.

DiPiazza, Francesca Davis. 2012. Friend me! 600 Years of Social Networking in America. Minneapolis, MN: Twenty-First Century Books.

This article is protected by copyright. All rights reserved. 
Donath, Judith. 2007. "Signals in Social Supernets." Journal of Computer-Mediated Communication 13(1): 231-251.

Driscoll, Kevin and Shawn Walker. 2014. "Working Within a Black Box: Transparency in the Collection and Production of Big Twitter Data." International Journal of Communication 8: $1745-1764$.

Duggan, Maeve, Amanda Lenhart, Cliff Lampe and Nicole Ellison. 2015. 'Parents and Social Media.' Pew Research Center. http://www.pewinternet.org/2015/07/16/parents-andsocial-media/

Earl, J. and Kimport, K., 2011. Digitally Enabled Social Change: Activism in the Internet Age. Boston: MIT Press.

Eichhorn, Kristen Campbell. 2008. "Soliciting and Providing Social Support Over the Internet: An Investigation of Online Eating Disorder Support Groups.” Journal of ComputerMediated Communication 14(1): 67-78.

Ellison, Nicole, \& boyd, danah. 2013. "Sociality through social network sites." Pp. 151-172 in The Oxford Handbook of Internet Studies, edited by William H. Dutton. Oxford, UK: Oxford University Press.

Enjolras, Bernard, Kari Steen-Johnsen, and Dag Wollebaek. 2012. "Social Media and Mobilization to Offline Demonstrations: Transcending Participatory Divides?" New Media \& Society 15(6): 890-908.

This article is protected by copyright. All rights reserved. 
Freelon, Deen, Charlton D. Mcilwain, and Meredith D. Clark. 2016. "Beyond the Hashtags: \#Ferguson, \#Blacklivesmatter, and the Online Struggle for Offline Justice." Center for Media \& Social Impact: 1-92.

Fuchs, Christian. 2012. "Social Media, Riots, and Revolutions." Capital \& Class 36(3): 383-391. Fuchs, Christian. 2014. Social Media: A Critical Introduction. London: Sage.

Garnham, David. 1992. "Democracy, War and Peace in the Middle East.” Digest of Middle East Studies 1(3): 1-7.

Goffman, Erving. 1959. The Presentation of Self in Everyday Life. Garden City, NY: Doubleday. Golder, Scott A., and Macy, Michael W. 2014. "Digital Footprints: Opportunities and Challenges for Online Social Research.” Sociology 40: 129-152.

Hänska-Ahy, Maximillian. 2014. "Networked Communication and the Arab Spring: Linking Broadcast and Social Media." New Media and Society 14: 1-18.

Hampton, Keith N., Laurent Sessions Goulet, Cameron Marlow and Lee Rainie. 2012. "Why Most Facebook Users Get More Than They Give.” Pew Research Center 3. Retrieved from: http://pewinternet.org/Reports/2012/Facebook-users.aspx

Hargittai, Eszter. 2008. 'Whose Space? Differences Among Users and Non-Users of Social Network Sites’ Journal of Computer-Mediated Communication 13: 276-297.

Hecht, Brent and Darren Gergle. 2010. “The Tower of Babel Meets Web 2.0: User-Generated Content and its Applications in a Multilingual Context." Pp. 291-300 in Proceedings of the SIGCHI Conference on Human Factors in Computing Systems. New York, NY: ACM.

This article is protected by copyright. All rights reserved. 
Heinonen, Kristina . 2011. “Consumer Activity in Social Media: Managerial Approaches to Consumers' Social Media Behavior.” Journal of Consumer Behavior 10(6): 356-364.

Herring, Susan, Lois Scheidt, Sabrina Bonus and Elijah Wright. 2004. "Bridging the Gap: A

Genre Analysis of Weblogs." Pp. 1-11 in Proceedings of the 37th Hawaii International

Conference on System Sciences. Los Alamitos, CA: IEEE.

Hogan, Bernie. 2010. “The Presentation of Self in the Age of Social Media: Distinguishing Performances and Exhibitions Online.” Bulletin of Science, Technology \& Society 30:

$377-386$.

Honeycutt, Courtenay and Susan Herring. 2009. "Beyond Microblogging: Conversation and Collaboration via Twitter." Pp. 1-10 in Proceedings of the 42nd Hawaii International Conference on System Sciences. Los Alamitos, CA: IEEE.

Humphreys, Lee, \& Rowan Wilken. 2015. "Social Media, Small Businesses, and the Control of Information.” Information, Communication \& Society 18(8): 295-309.

Jacobellis v. Ohio, 378 U.S. 184 (1964). Retrieved from: http://caselaw.findlaw.com/ussupreme-court/378/184.html

Kane, Gerald C., Maryam Alavi, Giuseppe Labianca, and Stephen Borgatti. 2014. "What's Different about Social Media Networks? A Framework and Research Agenda.” MIS Quarterly 38(1), 275-304.

Kaplan, Andreas M. and Michael Haenlein. 2010. "Users of the World, Unite! The Challenges and Opportunities of Social Media." Business Horizons 53(1): 59-68.

This article is protected by copyright. All rights reserved. 
Karr-Wisniewski, P. \& Lu, Y. (2010) "When More is Too Much: Operationalizing Technology Overload and Exploring its Impacts on Knowledge Worker Productivity." Computers in Human Behavior 26(5): 1061-1072.

Kietzmann, Jan H., Kristopher Hermkens, Ian P. McCarthy and Bruno S. Silvestre. 2011. "Social Media? Get serious! Understanding the Functional Building Blocks of Social Media." Business Horizons 54(3): 241-251.

Krishnamurthy, Sandeep and Wenyu Dou. 2008. "Note from Special Issue Editors: Advertising with User-Generated Content: A Framework and Research Agenda." Journal of Interactive Advertising 8(2): 1-4.

Kwak, Haewwon, Changhyun Lee, Hosung Park, and Sue Moon. 2010. "What is Twitter, a Social Network or a News Media?" Proceedings of the $19^{\text {th }}$ International Conference on the World Wide Web: 1-10.

Leung, Loius, 2013. "Generational Differences in Content Generation in Social Media: The Roles of the Gratifications Sought and of Narcissism." Computers in Human Behavior 29(3): 997-1006.

Litt, Eden. 2012. “Knock, Knock. Who's There? The Imagined Audience.” Journal of Broadcasting and Electronic Media 56(3): 330-345.

Liu, Brooke Fisher, Julia Daisy Fraustino and Yan Jin. 2015. “Social Media Use During Disasters: How Information Form and Source Influence Intended Behavioral Responses." Communication Research 1-21

This article is protected by copyright. All rights reserved. 
Mahrt, Merja and Michael Scharkow. 2013. "The Value of Big Data in Digital Media Research.” Journal of Broadcasting \& Electric Media 57(1): 20-33.

Manovich, Lev. 2011. "Trending: The Promises and the Challenges of Big Social Data".

In Debates in the Digital Humanities, Edited by: Matthew K. Gold, Minneapolis, MN: The University of Minnesota Press. Available at: http://www.manovich.net/DOCS/Manovich_trending_paper.pdf

Marwick, Alice E. and danah boyd. 2010. "I Tweet Honestly, I Tweet Passionately: Twitter Users, Context Collapse, and the Imagined Audience." New Media \& Society 13(1): 113133.

Mayer-Schoenberger, Viktor and Kenneth Cukier. 2013. Big Data: A Revolution that will Transform How We Live, Work, and Think. London: John Murray Publishers.

Murthy, Dhiraj. 2012. “Towards a Sociological Understanding of Social Media: Theorizing Twitter." Sociology 46: 1059-1073.

Nadkarni, Ashwini and Stefan G. Hofmann. 2012. "Why do People use Facebook?” Personality and Individual Differences 52: 243-249.

Niederer Sabine and José van Dijck. 2010. "Wisdom of the Crowd or Technicity of Content? Wikipedia as a Sociotechnical System.” New Media and Society 12(8): 1368-1387. Neves, Barbara B. 2013. "Social Capital and Internet Use: The Irrelevant, the Bad, and the Good.” Sociology Compass 7: 599-611.

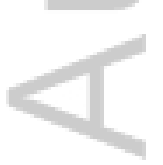

This article is protected by copyright. All rights reserved. 
Nonnecke, Blair and Jenny Preece. 2000. "Lurker Demographics: Counting the Silent.” Pp. 7380 in Proceedings of the SIGCHI Conference on Human Factors in Computing Systems. New York, NY: ACM.

O’Connor, Brendan, Ramnath Balasubramanyan, Bryan R. Routledge and Noah A. Smith. 2010. "From Tweets to Polls: Linking Text Sentiment to Public Opinion Time Series.” Pp. 122129 in Proceeding of the Fourth International AAAI Conference on Weblogs and Social Media.

Orlikowski, Wanda J. and JoAnne Yates. 1994. "Genre Repertoire: The Structuring of Communicative Practices.” Administrative Science Quarterly 39(4): 541-574.

Panciera, Katherine, Aaron Halfaker and Loren Terveen. 2009. "Wikipedians Are Born, Not Made: A Study of Power Editors on Wikipedia." Pp. 51-60 in Proceedings of the International Conference on Supporting Group Work. New York, NY: ACM.

Paul, Michael J. and Mark Dredze. 2011. "You Are What Your Tweet: Analyzing Twitter for Public Health.” Pp. 265-272 in Proceeding of the Fifth International AAAI Conference on Weblogs and Social Media.

Qualman, Erik. 2012. Socialnomics: How Social Media Transforms the Way We Live and Do Business. Hoboken, NJ: John Wiley and Sons.

Robards, Brady. 2012. 'Leaving MySpace, Joining Facebook-'Growing Up' on Social Network Sites." Continuит 26(3): 385-398.

This article is protected by copyright. All rights reserved. 
Robards, Brady and Andy Bennett. 2011. "MyTribe- Post-Subcultural Manifestations of Belonging on Social Network Sites." Sociology 45(2): 303-317.

Romero, Daniel, Wojciech Galuba, Sitaram Asur and Bernardo A. Huberman. 2011. "Influence and Passivity in Social Media." Proceedings of the $20^{\text {th }}$ International World Wide Web Conference.

Rotman, Dana, Jenny Preece, Jen Hammock, Kezee Procita, Derek Hansen, Cynthia Parr, Darcy Lewis and David Jacobs. 2012. "Dynamic Changes in Motivation in Collaborative Citizen-Science Projects.” Pp. 217-226 in Proceedings of the 2012 Conference on Computer Supported Cooperative Work. New York, NY: ACM.

Ryan, Tracii and Sophia Xenos. 2011. "Who Uses Facebook? An Investigation into the Relationship between the Big Five, Shyness, Narcissism, Loneliness, and Facebook Usage." Computers in Human Behavior 27(5). 1658-1664.

Shao, G. 2009. "Understanding the Appeal of User-Generated Media: A Uses and Gratification Perspective." Internet Research 19(1): 7-25.

Shaw, Bret R., Robert Hawkins, Fiona McTavish, Suzanne Pingree and David H. Gustafson. 2006. "Effects of insightful disclosure within computer mediated support groups on women with breast cancer." Health Communication 19(2): 133-142.

Shirky, Clay. 2011. "The Political Power of Social Media: Technology, the Public Sphere, and Political Change." Foreign Affairs 90(1): 28-41.

Siles, Ignacio. 2011. “The Rise of Blogging: Articulation as a Dynamic of Technological

This article is protected by copyright. All rights reserved. 
Stabilization." New Media and Society 14(7): 1-17.

Schradie, Jen. 2012. "The Trend of Class, Race, and Ethnicity in Social Media Inequality: Who Still Cannot Afford to Blog?” Information, Communication and Society 15: 555-571. Standage, Tom. 2013. Writing on the Wall: Social Media - The First 2,000 Years. New York, NY: Bloomsbury.

Stephens, Keri K. and Stephanie L. Dailey. 2014. "Human Resources Development in a Technology-Infused Workplace.” Pp. 3694-3702 in Encyclopedia of Information Science and Technology, edited by Mehdi Khosrow-Pour. Hershey, PA: IGI Global.

Stephansen, H. C., \& Couldry, N. (2014). “Understanding Micro-Processes of Community Building and Mutual Learning on Twitter: A 'Small Data' Approach.” Information, Communication \& Society 17(10): 1212-1227.

Sullivan, Andrew. 2009. "The Revolution will be Twittered." The Atlantic.

Tarafdar, Monideepa, Qiang Tu, Bhanu S. Ragu-Nathan and T.S. Ragu-Nathan. 2007. "The Impact of Technostress on Role Stress and Productivity.” Journal of Management Information Systems 1(24): 301-328.

Tinati, Ramine, Susan Halford, Leslie Carr, and Catherine Pope. 2014. "Big Data: Methodological Challenges and Approaches for Sociological Analysis." Sociology 48(4): $663-681$.

Treem, Jeffrey and Thomas Kristen. 2010. "What Makes a Blog a Blog? Exploring User Conceptualizations of an Old 'New' Online Medium.' Pp. 347-350 in Proceedings of the 
Fourth International AAAI Conference on Weblogs and Social Media.

Trottier, Daniel and Christian Fuchs. 2015. "Theorising Social Media, Politics and the State.” Pp. 3-38 in Social Media, Politics and the State: Protests, Revolutions, Riots, Crime and Policing in the age of Facebook, Twitter and Youtube, edited by Daniel Trottier and Christian Fuchs. New York, NY: Routledge.

Turcotte, Jason, Chance York, Jacob Irving, Rosanne M. Scholl and Raymond J. Pingree. 2015. "News Recommendations from Social Media Opinion Leaders: Effects on Media Trust and Information Seeking." Journal of Computer-Mediated Communication 20(5): 520535.

Tustin, Nupur. 2010. "The Role of Patient Satisfaction in Online Health Information Seeking." Journal of Health Communication: International Perspectives 15(1): 3-17.

Van Dijck, José. 2011. “Tracing Twitter- The Rise of a Microblogging Platform.” International Journal of Media \& Cultural Politics, 7(3): 333-348.

van Dijck, José. 2013. “'You Have One Identity’: Performing the Self on Facebook and LinkedIn.” Media, Culture \& Society: 35(2): 199-215.

van Dijck, José. 2014. "Datafication, Dataism and Dataveillance: Big Data between Scientific Paradigm and Ideology." Surveillance \& Society: 1-15.

van Dijck, José and Thomas Poell. 2013. "Understanding Social Media Logic.” Media and Communication 1(1): 2-14.

This article is protected by copyright. All rights reserved. 
Wegner, E. (1998). Communities of Practice: Learning, Meaning, and Identity. Cambridge: Cambridge University Press.

Willis, Suzanne and Tranter, Bruce. 2006. “Beyond the 'Digital Divide:' Internet Diffusion and Inequality in Australia.” Journal of Sociology 42: 43-59.

Yardi, Sarita, Scott A. Golder and Michael Brzozowski. 2009. "Blogging at Work and the Corporate Attention Economy" Pp. 2071-2080 in Proceedings of the 27th International Conference on Human Factor in Computing Systems.

Zhao, Shanyang and Elesh, David. 2007. "The Second Digital Divide: Unequal Access to Social Capital in the Online World." International Review of Modern Sociology 33: 171-192. Zhao, Shanyang, Sherri Grasmuck and Jason Martin. 2008. "Identity Construction on Facebook: Digital Empowerment in Anchored Relationships." Computers in Human Behavior 24: 1816-1836.

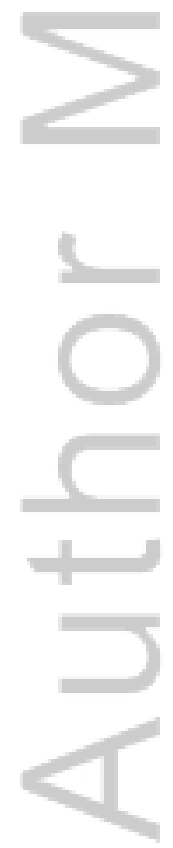

This article is protected by copyright. All rights reserved. 